\title{
A Study of the Performance Evaluation for Airline Operation
}

\author{
Gin-Shuh Liang* Tsung-Yu Chou** Shan-Shan Chuang* \\ * Department of Shipping and Transportation Management, National Taiwan Ocean University \\ gasliang@mail.ntou.edu.tw \\ ** Department of Marketing and Logistics Management, National Penghu University \\ cjy920@ms49.hinet.net
}

\begin{abstract}
Combining the concepts of balanced scorecard, fuzzy set theory and entropy, a systematic fuzzy multiple criteria decision making (MCDM) for airlines operating performance evaluation is proposed. A hierarchical structure is constructed through the concept of balance scorecard includes four perspectives: finance, customers, internal business processes, and learning and growth. The triangular fuzzy numbers are used to denote the weights of all criteria and the evaluation values of all alternative airlines versus subjective and objective criteria. For effectively measuring the average essence of information quantity, the entropy weighting method is utilized to modify the weights of subjective criteria. Thus, the explanation ability and reliability of criteria can be effectively conveyed.
\end{abstract}

Keywords: Air transport, Fuzzy set theory, Fuzzy MCDM, Entropy, Relatedness measures, Balance scorecard

\section{Introduction}

Traditionally, the literatures concerning companies’ operation performance focus on financial performance factor, such as profit ratio and sales growth ratio. This is incompleteness because many non-financial performance factors, such as customer satisfaction, employee satisfaction, and operating efficiency, are important with companies' future success. Consequently, lots of academic professions try to search an optimal performance evaluation model in other than financial factor.

The Balanced Scorecard (Kaplan and Norton, 1996) has four distinct but related perspectives: financial, customer, internal business process, and learning and growth. This new performance measure system balances not only the financial and non-financial measures, but also the short-term and long-term objectives of organizations. Kaplan and Norton (1996) believe if organizations better the working environment for learning and growth shall satisfy their employees, and that in turn facilitate the manufacture processes and provide quality products and services to customers. With pleased customers, organizations will have the opportunity to expand their businesses that finally result in financial performance improvement. Combine with the characteristics of air transportation, a multi-criteria evaluation model is built to evaluate the operation performance of airlines.

Generally, the multi-criteria problems are fuzzy. 
It is difficult to transmit the character and significance of criteria exactly or clearly by traditional methods. While using the concept of fuzzy sets theory and natural language to evaluate organization performance will bring convenience, which make responders can express their ideas freely and adequately. Accordingly, we combine fuzzy sets theory and entropy concept to set up a model that can provide decision makers to deal with complex issues under fuzzy environment. Thus, a fuzziness-based decision model for airline companies is more appropriate and effective than traditional precision-based models. Therefore, this paper proposes an easy handling and practical performance evaluation model, a fuzzy multi-criteria evaluation model.

\section{Research methods}

In this paper, triangular fuzzy numbers are utilized to characterize the fuzzy sense concerning to the weights of all criteria, ratings of all alternatives, and the measures of relative similarity degree of all alternatives. The entropy weighting method (Zeleng, 1982) is used to adjust the subjective weights of all objective sub-criteria.

\section{Procedure for airline performance evaluation}

The procedure for airline performance evaluation proposed in this paper can be summarized as follow.

\subsection{Select criteria}

The concept of balance scorecard is applied to develop the performance evaluation criteria. According to lectures review and considering the character of air transportation, 23 evaluation criteria are selected through four perspectives: finance, customer, internal business processes, learning and growth (Table 1).

\subsection{Solve subjective weight of all criteria}

Let $a_{j k}, k=1,2, \cdots, n$, be the numerical weightings given to criteria $j$ by decision-maker $k$. Then, the fuzzy subjective weight of the criterion $\mathrm{j}$ is defined as $B_{j}=\left(c_{j}, a_{j}, b_{j}\right)$, where

$c_{j}=\min \left\{a_{j 1}, a_{j 2}, \cdots, a_{j n}\right\}, a_{j}=\left(\prod_{k=1}^{n} a_{j k}\right)^{1 / n}$, $b_{j}=\max \left\{a_{j 1}, a_{j 2}, \cdots, a_{j n}\right\}$.

\subsection{Estimate the fuzzy ratings of all alternatives}

\section{versus all sub-criteria above alternative level}

For the objective criteria, the triangular fuzzy numbers can be used directly. Another way one can use the historical data to construct the evaluation value, e.g., let $a_{1}, a_{2}, \ldots, a_{t}$, represent the return on equity of past $t$ periods, the fuzzy rating of return on equity can be expressed as

$$
\left(\min _{i}\left\{a_{i}\right\},\left(\prod_{i=1}^{t} a_{i}\right)^{1 / t}, \max _{i}\left\{a_{i}\right\}\right)
$$

\subsection{Solve the relatedness measure of alternatives}

The measure of relative similarity degree $C R\left(A_{i}\right)$ of $m$ matters represented by triangular fuzzy numbers can be calculated: 
$C R\left(A_{i}\right)=A V\left(A_{i}\right) / \sum_{i=1}^{n} A V\left(A_{i}\right), i=1,2, \ldots, m$, where $A V\left(A_{i}\right)=\frac{1}{m-1} \sum_{j=1}^{m} \delta_{M}\left(A_{i}, A_{j}\right)$,

$\delta_{M}\left(A_{i}, A_{j}\right)=\left\{1 / 4\left[\left(c_{i}-c_{j}\right)^{2}+2\left(a_{i}-a_{j}\right)^{2}+\left(b_{i}-b_{j}\right)^{2}\right]\right\}^{1 / 2}$

$$
\text { , } A_{i}=\left(c_{i}, a_{i}, b_{i}\right) \text { and } A_{j}=\left(c_{j}, a_{j}, b_{j}\right) \text {. }
$$

Table 1. The criteria for performance evaluation

\begin{tabular}{|c|c|c|}
\hline Perspective & Number & Criteria \\
\hline \multirow[t]{4}{*}{ Finance } & $C_{11}$ & $\begin{array}{l}\text { Return on common stock - } \\
\text { holders' equity }\end{array}$ \\
\hline & $C_{12}$ & Net income ratio \\
\hline & $C_{13}$ & Return on assets \\
\hline & $C_{14}$ & Return on investment \\
\hline \multirow[t]{7}{*}{ Customer } & $C_{21}$ & Market share \\
\hline & $C_{22}$ & Passenger-kilometers \\
\hline & $C_{23}$ & Ratio of passengers carried \\
\hline & $C_{24}$ & Profession satisfaction \\
\hline & $C_{25}$ & Service satisfaction \\
\hline & $C_{26}$ & Transportation satisfaction \\
\hline & $C_{27}$ & $\begin{array}{l}\text { The willingness of consuming } \\
\text { again }\end{array}$ \\
\hline \multirow{9}{*}{$\begin{array}{l}\text { Internal } \\
\text { business } \\
\text { processes }\end{array}$} & $C_{31}$ & $\begin{array}{l}\text { The ability of developing new } \\
\text { processes and new services }\end{array}$ \\
\hline & $C_{32}$ & $\begin{array}{l}\text { The ability of new passengers } \\
\text { creating }\end{array}$ \\
\hline & $C_{33}$ & $\begin{array}{l}\text { The ability of collecting } \\
\text { market information quickly } \\
\text { and correctly }\end{array}$ \\
\hline & $C_{34}$ & $\begin{array}{ll}\text { Staffs' } & \text { professional } \\
\text { knowledge } & \end{array}$ \\
\hline & $C_{35}$ & Ratio of flight on schedule \\
\hline & $C_{36}$ & Total seats available \\
\hline & $C_{37}$ & $\begin{array}{l}\text { Ability of providing enough } \\
\text { seats }\end{array}$ \\
\hline & $C_{38}$ & $\begin{array}{l}\text { Establishing special telephone } \\
\text { lines for handling passengers' } \\
\text { complaint }\end{array}$ \\
\hline & $C_{39}$ & $\begin{array}{l}\text { Providing perfect booking } \\
\text { and consulting service }\end{array}$ \\
\hline \multirow[t]{3}{*}{$\begin{array}{l}\text { Learning } \\
\text { and growth }\end{array}$} & $C_{41}$ & $\begin{array}{l}\text { The enhancement of staffs' } \\
\text { professional and customer } \\
\text { service ability }\end{array}$ \\
\hline & $C_{42}$ & $\begin{array}{l}\text { The enhancement of } \\
\text { information technology } \\
\text { ability }\end{array}$ \\
\hline & $C_{43}$ & $\begin{array}{l}\text { The enhancement of the } \\
\text { consistency of duty, goal and } \\
\text { encouragement }\end{array}$ \\
\hline
\end{tabular}

3.5 Utilize entropy weighting method to adjust the

\section{subjective weight of objective sub-criteria}

Let a criterion above alternative level include $r$ criteria. Suppose there are $p$ objective criteria $p \leq r$, such that $v_{j}, j=1,2, \cdots p$, are the subjective weights of objective criteria. $\lambda_{j}, j=1,2, \cdots, p$, are the objective weights of $p$ criteria obtained by using entropy method (Zeleng, 1992). Then, the weight $w_{j}$ of the $j^{\text {th }}$ objective criterion can be obtained:

$$
w_{j}=\left(\sum_{j=1}^{p} v_{j}\right) \otimes\left(v_{j}^{*}\right)=\left(\sum_{j=1}^{p} v_{j}\right) \otimes\left[\left(\lambda_{j} \otimes v_{j}\right) \varnothing\left(\sum_{j=1}^{p} \lambda_{j} \otimes v_{j}\right)\right]
$$

, $j=1,2, \cdots, p$.

where $v_{j}^{*}=\frac{\lambda_{j} v_{j}}{\sum_{j=1}^{p} \lambda_{j} v_{j}}, j=1,2, \cdots, p$.

\subsection{Calculate the integrated evaluation values of}

\section{all alternatives}

Let $w_{t}=\left(c_{t}, a_{t}, b_{t}\right), t=1,2, \cdots, k$, be the weights of criteria on the first level. And let $w_{t j}=\left(c_{t j}, a_{t j}, b_{t j}\right) \quad, \quad t=1,2, \cdots, k \quad ;$ $j=1,2, \cdots, n_{t}$ be the weights of all criteria $\left(\sum_{t=1}^{k} n_{t}\right)$ on the second level that have been adjusted by entropy weighting method.

$$
\text { Let } S_{i t j}=\left(p_{i t j}, o_{i t j}, q_{i t j}\right), i=1,2, \cdots, m \text {, }
$$

$t=1,2, \cdots, k, j=1,2, \cdots, n_{t}$, be the normalizing advantage evaluation value of $j^{\text {th }}$ sub-criterion on the second level under $t^{\text {th }}$ criterion of the first level in $i^{\text {th }}$ company.

Then, the integrated advantage evaluation values $F_{i}$ of airline $i$ versus all $k$ criteria can be obtained: 
$F_{i}=\frac{1}{k} \otimes\left[\left(R_{i 1} \otimes w_{1}\right) \oplus\left(R_{i 2} \otimes w_{2}\right) \oplus \cdots \oplus\left(R_{i k} \otimes w_{k}\right)\right]$

where $R_{i t}$ is the integrated advantage evaluation

value of $i^{\text {th }}$ airline versus the $t^{\text {th }}(t=1,2, \cdots, k)$

criterion, and

$R_{i t}=\frac{1}{n_{t}} \otimes\left[\left(S_{i t 1} \otimes w_{t 1}\right) \oplus\left(S_{i t 2} \otimes w_{t 2}\right) \oplus \cdots \oplus\left(S_{i t n_{i}} \otimes w_{t n_{i}}\right)\right]$

Finally, based on the integrated advantage evaluation

values of all airlines and the appropriate ranking

method constructed on the triangular fuzzy numbers,

the best airline can be chosen.

\section{Conclusion}

The purpose of this research is to build a systematic and suitable performance evaluation model for airline operation. At first, the concept of balance scorecard is used to construct performance evaluation criteria under four perspectives: finance, customer, internal business processes, and learning and growth. To phase the balance scorecard concept in enterprise not only replenish the evaluation criteria ignored, but also make the selection of evaluation criteria completely. For solving the difference caused by subjective expression, this research utilizes triangular fuzzy number to deal with the weights' evaluation of criteria to meet the fuzzy environment. Besides, the entropy weighting method is adopted to adjust the weights of objective criteria to make the explanation ability and reliability of objective criteria more effective.

The merits of the performance evaluation model are that it can not only release the limitation of crisp evaluation value, but also facilitate its implementation as a computer-based decision support system for solving practical airline performance evaluation problem in a fuzzy environment.

\section{References}

[1] Hsieh, C.H., Chen, S.H., 1999. A Model and Algorithm of Fuzzy Product Positioning, Information Sciences, 121, 61-82.

[2] Kaplan, R.S., Norton, D.P., 1996. The Balanced Scorecard: Translating Strategy Into Action, Harvard Business School Press.

[3] Saaty, T.L., 1980. The analytic hierarchy process, McGraw-hill: NY.

[4] Zadeh, L.A., 1965. Fuzzy Sets, Information and Control, 8, 338-353.

[5] Zeleng, M., 1982. Multiple Criteria Decision Making, McGraw-Hill Book Company. 